\title{
Cultivation of Marine Sponges with Pharmaceutical Value: Status and Future Prospects in India
}

\author{
R. Kiruba-Sankar ${ }^{1 *}$, K. Vinod ${ }^{2}$, S. Dam Roy ${ }^{1}$, P. Krishnan ${ }^{3}$, N.K. Chadha ${ }^{4}$, \\ Paramita Banerjee Sawant $^{4}$ and Neelam Saharan ${ }^{4}$
}

\author{
${ }^{1}$ Fisheries Science Division, ICAR- Central Island Agricultural Research Institute, \\ Port Blair, Andaman and Nicobar Islands \\ ${ }^{2}$ ICAR-Central Marine Fisheries Research Institute, Kochi, India \\ ${ }^{3}$ ICAR-National Academy of Agricultural Research Management, Hyderabad, India \\ ${ }^{4}$ ICAR-Central Institute of Fisheries Education, Mumbai, India \\ *Corresponding author
}

A B S T R A C T

\begin{tabular}{|l|}
\hline Key w or d s \\
Bioactive \\
compounds, \\
Drugs, Mariculture, \\
Sponges
\end{tabular}

This article reviews the importance of culturing marine sponges, considering its applications in the field of drug development and pharmaceutics. Although the biomedical potential of sponges is known, sponge mariculture is an unexplored field in India. Sponges produce bioactive metabolites which have potential applications in drug development, as since sponges yield very low amount of bioactive compounds, mariculture technologies are to be standardized in order to ensure steady supply of sponges in required quantities without disturbing the wild sponge populations. The review also reveals several candidate sponges in India like Stylissa massa, Hyrtios erectus, Mycale sp., Dysidea sp. and Plakortis sp. with reports of high bioactive potential, and can be taken up for mariculture. The possibilities of fish-sponge integrated aquaculture are also discussed as opportunities. With the emergence of rare and uncommon diseases, marine organisms, particularly sponges hold much promise to resolve critical issues in the field of drug development. The review calls on importance in demonstration of feasible mariculture technology of potential candidate marine sponges in India, which could cater to the pharmaceutical needs, without disturbing their wild population.

\section{Introduction}

Marine environment hosts innumerable flora and fauna which offers various livelihood and ecosystem services across the globe. Clearly the world's oceans will play an important part in the future control of the global infectious disease burden (Laport et al., 2009). Sponges are one of the most important invertebrates considering its pharmaceutical and drug development prospective, as they are known to produce bioactive secondary metabolites
(Koopmans et al., 2011). The interest in sponges has increased rapidly since the discovery of pharmaceutical compounds produced by many of them (Koopmans 2009). Among the marine organisms, sponges have proved to be the best source of biologically active metabolites for use as drug leads or biomedical tools (Ireland et al., 1993). Microbiologists became fascinated by these unique animals with the discovery of 
abundant unusual microorganisms (Thakur and Muller, 2004). Sponges, if propagated sustainably could help to produce several compounds which could play an important role in curing many diseases. With increasing trends of diseases, particularly cancer being a global concern, sponges have the potential to provide drugs against viral diseases, inflammation and malaria (Sipkema et al., 2005a). More than 5300 different products have been recorded from sponges and their associated microorganisms, and every year around 200 new metabolites are reported (Lipton and Shine, 2009). Globally 11,000 sponges have been described of which 8,500 are considered valid (Vansoest et al., 2012).

The first effort for in situ aquaculture of marine sponges (bath sponges) was achieved in Adriatic Sea in 1870 (Tommonaro et al., 2015) with no detailed report. Historical details by (Crawshay, 1939) reveal early attempts in sponge culture by Cavolini in 1785 and 1790, followed by Schmidt in 1862, Bucchich in 1864, and Harris in 1897 as none of these experiments yielded any serviceable data (Crawshay, 1939). Detailed studies on sponge culture back in early 1900's by (Moore, 1910; Crawshay, 1939) and detailed review of sponge farming by Osinga et al., (1999), Duckworth (2009), Yi et al., (2005) and Schippers et al., (2012) have given more insights on sponge farming methods and its importance across the world. Macmillan (1996) in his report on setting up of commercial sponge farm describes sponge culture as easy, profitable and environment friendly.

India is one of the rich spots of sponge diversity among 232 marine ecoregions of the world (Vansoest et al., 2012). Though globally sponge aquaculture has been gaining importance owing to its applications, sponge mariculture is relatively an unchartered area in Indian mariculture sector in comparison with marine fin fishes, shell fishes and bivalves, although small-scale attempts on sponge culture were reported from India during 2009 and 2016. Sponge aquaculture is still at infancy in India (Vinod et al., 2009); though the country is blessed with great diversity of sponges particularly in the Gulf of Mannar, Palk Bay and Andaman Islands, the studies concentrate more on their bioactive compounds. The sponge fauna of India is dominated by species of Demospongia followed by Hyalospongiae and Calciospongiae (Venkataraman, 2005) and the Gulf of Mannar and Palk Bay along the southeast coast account for over $67 \%$ of sponge diversity of India (Sivaleela, 2014). In India, 486 species of sponges were reported (Thomas, 1998) wherein the Gulf of Mannar and Palk Bay has the highest number of species (319 species) followed by Andaman and Nicobar Islands (95 species), Lakshadweep (82 species) and the Gulf of Kachchh (25 species) (Venkataraman, 2005). A recent report on the sponge diversity in India by Chandra et al., 2016 updates 476 species among which the Palk Bay and the Gulf Mannar has the highest (329), followed by Andaman and Nicobar (126). Though systematic inventory of sponges in India has been stressed (Wilson and Kitto, 2012), their mariculture potential has not been given due attention. The review highlights the importance of sponge cultivation in India considering its vast applications and to take necessary steps as preparatory action for future as sponge possess metabolites which can be utilized for producing life-saving drugs.

\section{Applications of marine sponges}

The incidence of emerging infectious diseases in humans has increased within the recent past or threatens to increase in the near future (Dikid et al., 2013) and sponges hold much promise in developing a potential cure. 
Sponges were shown to possess numerous roles as anti-inflammatory, anti-tumour, immuno-suppressive, as cardiovascular agents, neuro suppressive, muscle relaxants, anti-viral, anti-malarial, anti-fouling, antibiotics and as fungicides (reviewed by Sipkema et al., 2005a; Anjum et al., 2016). Sponges have potential as anti-cancer and anti-mitotic (Munro et al., 1999), antiprotozoal activity (Laport et al., 2009), antiviral and Ara-C (Arabinosysl Cytosine) - an anti-tumour compound marketed by Pharmacia \& Upjohn Company in the brand name Cytosar-UR (Thakur and Muller, 2004). They also have potential anti-malarial, antimicrobial and cytotoxic properties (Pedpradab et al., 2010).

The secondary metabolites of some sponges are known to inhibit cancerous growth and diseases (Longakit et al., 2005). They are anti-tumour (Tasdemir et al., 2002; Gordaliza, 2010) have potent antileukemic activity (Muller et al., 1985), inhibitory activity against hepatocellular carcinoma, colorectal carcinoma and breast adenocarcinoma cells (Elhady et al., 2016). They are used for the treatment of psoriasis (Pietschmann et al., 2004), as anti foulant (Pereira et al., 2002; Riberio et al., 2012), in cosmetics (Swatschek et al., 2002), for marine environmental bioremediation in integrated aquaculture practices (Milanese et al., 2003), bioremediation in polluted sea water (Stabili et al., 2006), to clear large volume of water of organic and bacterial loads in polluted sites (Ledda et al., 2014) as their pumping activity might play an important role in water purification. They are used in the biosynthesis of silver nanoparticles (Inbakandan et al., 2012) as silver nanoparticles are being investigated as tools for novel cancer therapeutics (Ong et al., 2013). The sponges serve as pollution bio indicators (Caraballo 1996; Devoogd 2008; Muricy, 1989; KirubaSankar et al., 2016). They are antibacterial sources for managing shrimp diseases (Selvin and Lipton, 2004a).

Sponges are also known to contribute substantially to the healthy functioning of coral reefs (Diaz and Rutzler, 2001). In India, sponges and associated microbes were studied for their anti-microbial properties (Sonia et al., 2008; Devi et al., 2011; Chairman et al.,2012; Dhinakaran and Lipton, 2012; Suman et al., 2013; Krishnan et al., 2014a, b; Vijayalakshmi, 2015) and mosquito larvicidal properties (Sonia and Lipton, 2012), antiinflammatory (Kumar et al., 2014), immunomodulatory activity (Krishnan and Keerthi, 2016), anti-tumour (Chairman and Singh, 2013) and anti-cancer properties (Annamalai et al., 2015). Sponge microbe interactions were also discussed in view of bioprospecting and ecological implications (Selvin et al., 2010). Stevely et al., (1978) reports several other uses of sponges by painters, lithographers, janitors, artists, leather workers, window cleaners, in automotive fields, tile setters and in hospitals. Sponges were also shown to have numerous functional roles particularly bioerosion, reef creation, substrate stabilization, carbon cycling, silicon cycling, nitrogen cycling, primary production, secondary production, camouflaging, etc. (reviewed by Bell, 2008). The potential application of sponges are extensive without doubt; however, the actual issue is the supply of requisite biomass (Osinga et al., 1999; Thakur and Muller, 2004) as these invertebrates produce metabolites in trace quantities.

\section{Need for mariculture of sponges}

Sipkema et al., (2005a) raised question for future on how to actually prepare the potential novel drugs on a large scale. For instance, the marine sponge Dysidea avara produces avarol which is a very important metabolite with various applications. This sponge is known to 
contain $2 \mathrm{~g}$ of avarol per $\mathrm{kg}$ wet weight, and therefore a total of 75 tons of sponge would be required to sustain market demand (Sipkema et al., 2005b). Selvin and Lipton (2004) reported recovery of bioactive extracts of marine sponges Axinella donnani $(8 \mathrm{~g} / \mathrm{kg})$, Dendrilla nigra $(6 \mathrm{~g} / \mathrm{kg})$ and Clathria gorgonoides $(3.8 \mathrm{~g} / \mathrm{kg})$.

Sponges produce bioactive compounds as a defence mechanism against fouling, predation and to compete for space (Becerro et al., 1997). Having such potential and numerous applications in various fields, and production of metabolites in trace quantities creates an issue with respect to mass production. Very large quantities of sponges are to be exploited in order to produce considerable quantity of required metabolites. Until mass production is demonstrated, the technologies will not be feasible, particularly when such compounds are required for drug development and pharmaceutical purpose. The available natural population of sponges will not be sufficient enough for utilization as exploitation from the wild could threaten the existing natural stock. Aquaculture of sponges is the only option to address the supply problem (Laport et al., 2009) to produce large quantity of requisite biomass.

Sponges have been experimentally farmed for over 100 years with early attempts done in the sea to supply bath sponges (Duckworth, 2009). In commercial sponge aquaculture, the major requirements include production of required quantities of sponge biomass and to promote or retain high biosynthesis of target bioactive metabolites (Duckworth and Battershill, 2003a). Farming of potential species would also minimize the pressure of over harvesting from wild (Vinod et al., 2009). Due to the difficulty in obtaining steady supply of such metabolites, only few of these compounds have reached clinical trial stage (Hadas et al., 2005).

\section{Sponge mariculture: Global}

Commercial sponging originated from the Aegean Islands of eastern Mediterranean Sea as until 1841, world sponge supply was solely derived from Mediterranean Sea (Stevely et al., 1978). Subsequently, it extended to several parts of the world owing to the realization of its importance in commercial market. Sponges can regenerate from small cut pieces making them potential for commercial farming. Their extensive regenerative capabilities play an important role in nature as well as in cultivation methods. Aquaculture from explants is one of the preferred cultivation methods as explants show great capacity to regenerate after fragmentation (Decaralt et al., 2003) and sponges also have quick damage response (Koopmans et al., 2011). Explants generally grow more rapidly than do whole sponge transplants (Kinne, 1977) and explants preparation details are reported by (Macmillan, 1996). Globally, several attempts have been made on sponge culture and Moore (1910) gave detailed description on the importance of sponge culture in one of the earliest studies and expressed concerns on damage of sponge beds due to destructive fishing practices especially in places like Florida, Bahamas, Cuba and in the Mediterranean Sea due to fishing pressure and sponge diseases (Pronzato et al., 1999). He described basic sponge culture methods in sea by using sponge cuttings attached to aluminium wire with artificial substrate in sea. The procedures described by Moore (1910) are still being used worldwide to produce commercial bath sponges (Osinga et al., 1999).

Sponge culture was attempted for several species either in situ or ex situ or in combinations as demonstrated in Tethya citrina (Bari et al., 2014), Spongia tubulifera and S. pertusa (Oronti et al.,2012), Stylissa 
massa, Neopetrosia spp. (Schiefenhovel and Kunzmann, 2012), Dysidea avara, Chondrosia reniformis (Nickel and Brummer, 2003; Osinga et al., 2010; Decaralt et al., 2010), Callyspongia subarmigera, Echninodictyum gorgonoides (Lipton and Shine, 2009), Negombata magnifica, Amphimedon chloros, Theonella swinhoei (Hadas et al., 2005; Bergman et al., 2011) Crambe crambe (Belarbi et al., 2003), deep water boreal sponge Geodia barretti (Hoffmann et al., 2003), mariculture of fishes(Sea bass) with sponge (Osinga et al., 2010), Ephydatia fluviatilis (Francis et al., 1990), Aaptos suberitoides, Amphimedon paraviridis, Callyspongia biru, Hyrtios reticulates, Ircinia ramose, Pseudoceratina verrucosa (Devoogd, 2007a), sponge larval culture (Decaralt et al., 2007) early juveniles of Hymeniacidon perlevis (Xue and Zhang, 2009)and many other morphologically distinct sponge species. Since sponges are slow growing organisms, a culture period of minimum 1 or 2 years would be required to achieve commercial size. Results of Stevely and Sweat (1985) demonstrate that at least 2 years are required for the surviving sponge base to regrow to a minimum commercial size. Survival rates of $90 \%$ are recommended as economic for sponge cultivation (Verdenal and Vacelet, 1990). Higher survival rates of over $90 \%$ was recorded in cases of Dysidea avara and Chondrosia reniformes (Osinga et al., 2010; Page et al., 2005) in New Zealand, $80-96 \%$ for $M$. hentscheli in Indonesia (Devoogd, 2007a), 80-100\% for Indonesian reef dwelling sponges (Devoogd, 2007b) and $81.1 \%$ for Tethya citrina (Bari et al., 2014). Close to $100 \%$ survival rates were obtained in explant culture of sponges (Decaralt et al., 2003).

Growth rate is also an important factor which determines the culture potential of sponges. As sponges are slow growing organisms, long-term culture methods are prerequisite to harvest sponges in high volume. Higher growth rates of $5000 \%$ in short term of one month is also achieved in sponge Lissodendoryx sp. in New Zealand (Battershill and Page, 1996) whereas Spongia officinalis has shown growth of double their weight in one year (Verdenal and Vacelet, 1990) and Chondrosia reniformis achieved $800 \%$ growth per year (Osinga et al., 2010). Larval culture being one exciting development in sponge culture (Duckworth, 2009) was attempted by Xue and Zhang (2009) and Decaralt et al., (2007) and found that larval culture under controlled conditions was better than open sea culture for preventing biomass loss in early juvenile sponges (Decaralt et al., 2007). Hadas et al., (2005) reports that sea ranching appears to be the most promising and applicable method aimed at production of sponge biomass. Sponge artificial seed rearing could provide a sustainable means of seed supply for sea based aquaculture or controlled biotechnological cultivation of sponge biomass (Xue and Zhang, 2009).

Disease outbreaks in sponge were reported in the Mediterranean and Caribbean Sea (Pronzato et al., 1999). Osinga et al., (1999) reported that increase in temperature makes the sponge susceptible to pathogen infections. Osinga et al., (2003) also discussed the unreliability of natural environment including disease outbreak which may affect productivity. Sponge diseases are catastrophic epidemics (Pronzato, 1999) and increased prevalence of sponge diseases in Papua New Guinea, Great Barrier Reefs and Mexico were reported with evidences of sponge diseases in relation with climate change and agricultural/urban runoff (Webster, 2007).

\section{Factors influencing sponge culture}

Farm site selection and identifying favourable environmental conditions that promote 
growth and survival are important to promote the commercial success of bath sponge farm (Duckworth et al., 2007). Survival and growth rates of sponges also depend on the season and physical conditions of the site. Several factors might influence the sponge farming as finding the exact requirement could be difficult. Water flow, depth and season are the main environmental factors that could influence the sponge farming (Duckworth et al., 2004). Being filter feeders, water flow could be an important factor for sponge growth and even in case of early juveniles of Hymeniacidon perlevis, periodic water flow and light illumination were found to stimulate the growth (Xue and Zhang, 2009). Water flow and food availability could influence sponge growth when farmed in water column (Duckworth, 2009). Duckworth et al., (2004) in culture of transplanted Latrunculia wellingtonensis and Polymastia croceus found that the survival was lowest in summer when the water temperature was highest and the growth of the transplanted explants was greatest overall at high flow site. Temperature changes were found to have striking effect on juvenile sponge growth (Xue and Zhang, 2009) and is an important factor affecting sponges, though commercial sponges appear to have tolerance between $10^{\circ} \mathrm{Cand} 35^{\circ} \mathrm{C}$ (Stevely et al., 1978).

The survival and growth rates of sponges under controlled conditions could be highly influenced by the food supply. Since sponges are filter feeders, the food availability could be aggravated by increased water flow. Even sponges have the ability to capture enough food during short period to sustain metabolism (Koopmans et al., 2011). Osinga et al., (1999) suggests that an adequate supply of food seems to be the key to successful sponge culture. Osinga et al., (2003) also suggests studying the role of vitamin in the food and its role in sponge metabolism, as its effect on growth and development of regenerating sponge explants is unknown. Stevely et al., (1978) reports that 'Mallee' a phenomenon caused by heavy growth of fine algae also killed shallow water sponges, as commercial value of sponges can also be greatly affected by the deformities caused by algae.

\section{Cultivation methods used for sponges}

Culture of sponges were attempted either in indoor or open sea conditions (Lipton and Shine, 2009; Schifenhovel and Kunzmann, 2012; Osinga et al., 2003). In situ and ex situ culture methods have its own advantages and disadvantages. Sea-based culture of sponges may be cheaper than land-based culture, since the land-based approach needs infrastructure to manipulate the culture environment. Duckworth (2009) also states that sea-based cultivation is the only commercially viable method. However, monitoring of the culture systems could be easier in the case of controlled conditions, whereas sea-based culture systems are vulnerable to environmental factors which might lead to loss of culture. Open sea conditions remain rough during monsoon with lot of inflow into the sea which also affects the sponge growth due to siltation. The culture system should be monitored periodically to avoid any possible loss of culture as for instance, Osinga et al., (2010) reports loss of culture after one year due to disruption of frame and some of the pins with the explants were found in the sediment around the frame. Duckworth (2009) suggests that land-based aquaculture is not likely to be commercially feasible in the near future in spite of having some positive results. Maintaining such long duration cultivation in indoor systems could be laborious and hence, extensive culture systems should be planned in open sea conditions using ropes (horizontal and vertical), frames, and small cages. However, Koopmans et al., (2009) suggests that apart 
from costs, sea-based culture is less desirable than land based culture as sea conditions cannot be controlled and sponges are vulnerable to diseases and parasites.

The sea-based cultivation is advantageous as sponges are known to have bioremediation potential (Milanese et al., 2003; Stabili et al., 2006; Ledda et al., 2014) due to their ability to filter high volumes of water. Kloppel et al., (2008) while conducting experiments on ex situ cultivation of Aplysina aerophoba found this method to be promising to maintain sponges and obtain their bioactive metabolites.

\section{Substrates for cultivation}

Several methods of cultivation were employed globally including in situ culture using concrete discs as artificial substratum with sponge pieces attached to aluminium wire (Moore, 1910), threaded rope separated by plastic spacers, pearl panel, mesh array (reviewed by Duckworth, 2009), explants cultured in horizontal polypropylene ropes to coral anchors, Japanese method of hanging sponges on vertical lines extending from bamboo rafts and along lines attached to beer bottle floats (Macmillan, 1996), stainless steel frame and cage, Shish kebab method (Osinga et al., 2010), Metal grids (Schifenhovel and Kunzmann, 2012), horizontal rope, small cage and glue to metallic frame (Decaralt et al., 2010), mesh arrays and rope array (Duckworth and Battershill, 2003 a \& b), suspension method (threading sponge fragments on rope) (Hadas et al., 2005), tray batteries moored to sea floor (Muller et al., 1999), lanterns (Scallop lantern $1 \mathrm{~m}$ in diameter with ten tiers supported by wire hoops and covered in $1.5 \mathrm{~cm}$ nylon mesh (Munro et al., 1999), iron cages (Sankar et al., 2016), ex situ cultivation using rectangular PVC bioreactors (Osinga et al., 2003), aquarium (Lipton and Shine 2009;
Schifenhovel and Kunzmann, 2012; Sankar et al., 2016), FRP tanks (Vinod et al., 2009) and cell culture (Sipkema et al., 2005b). Macmillan (1996) describes that horizontal line method used by most sponge farmers in Micronesia is probably the cheapest, easiest and versatile method to culture sponges.

The method used for culture will determine the growth and survival as these methods has their own advantages and disadvantages. Duckworth et al., (2009) in his experiments on sponges Coscinoderma sp. and Rhopaloiedes odorabile cultured in mesh panel and threaded line, found that sponge farmed in mesh panel generally had good shape and oval appearance, whereas sponges farmed on threaded line is of a shape which is not marketable. However, one advantage of farming sponges for metabolite is that the final explant shape is not important (Duckworth, 2009). Munro et al., (1999) cultured sponges in bags, trays, discs and lanterns and found that sponge cultured in trays or on discs did not grow well mainly due to fouling of plastic structures. The best farming method to commercially grow bath sponges will vary between sponge species and regions (Duckworth, 2009). Sponges may also respond differently in growth and survival with respect to the culture method employed as different species require different culture techniques. Interesting observations were made by Stevely and Sweat (1985) with respect to culture of sponges using cut and hooked methods and found that $71 \%$ of cut sponges and $41 \%$ of hooked sponges were alive after 28 months of study and recommended both cut and hooked sponge culture method to attain commercially harvestable size with higher survival rates.

\section{Measuring growth of sponges}

One of the major issues with respect to sponge culture is the measurement of growth 
of sponges. There is no ambiguous method to determine the sponge biomass as determining biomass is one of the critical aspects of sponge culture (Osinga et al., 1999; Yi et al., 2005). The growth behaviour of sponges was also poorly understood owing to the fact that it exhibits irregular growth pattern and measuring their growth might be accompanied with certain degree of error. Several methods like underwater weight, film scan, 3D photogrammetry, outline scan, ruler measurement, spicule measurement, and surface area determination are used. Methods such as wet weights (Hoffmann et al., 2003; Hadas et al., 2005), length, width and height using ruler for sponge explants volume (Duckworth and Battershill, 2003b), sponge diameter (Stevely and Sweat, 1985), height measurement (Vinod et al., 2009), estimation of surface area using length and width measurement of sponge explants (Osinga et al., 2010), image analysis to quantify the increase in area (Decaralt et al., 2007), 3Dphotogrammetry technique (Koopmans, 2009), mean volume of explants (Schifenhovel and Kunzmann, 2012), underwater weight (Osinga et al., 2003). Measuring wet weight could be destructive to sponges as sponges are filter feeders and if we remove them out of water it could lead to mortality. Also, wet weight of sponges could not be considered as indicator of growth due to irregular water retention by the aquiferous system (Stone, 1970). Measurement using ruler could be simple but the accompanying error could be large (Yi et al., 2005).

\section{Sponge mariculture: India}

Only three research studies have been reported in India to cultivate sponges (Lipton and Shine, 2009; Vinod et al., 2009; Sankar et al., 2016) and all the studies were of shortterm nature of less than four months. The sponge diversity of India is rich and unique, concentrated mainly in the Gulf of Mannar and Palk Bay regions. Sponge aquaculture though having high prospects and potential is in very early stage of development in India. Mariculture technologies has been developing at a steady pace in India and technologies for culture of selected species of fin fishes, crustaceans, bivalves, molluscs and sea weeds has been well standardized. Sea weeds cultivated in Mandapam coast of Tamil Nadu has been contributing as significant source of livelihood to the coastal women. Duckworth (2009) suggests that sponge culture could be of great potential to underdeveloped coastal communities as alternative source of income. Lipton and Shine (2009) cultured Callyspongia subarmigera, C. diffusa and Echniodictyum gorgonoides in Kerala coast in recirculatory semi enclosed aquaria and open sea conditions using explants. In open sea, Callyspongia subarmigera grew at an average of $88.94 \mathrm{mg}$ per day, with an overall growth of $93.37 \%$ compared to the initially stocked sponge tissue. In laboratory culture system, the sponges were fed with microalgae Nanochloropsis sp. twice a day. The study emphasizes that farming environment is an important factor for survival and growth. Callyspongia subargimera collected locally survived the farming conditions and was alive throughout the culture period whereas the other two species has not survived since transported from elsewhere and cultured. The culture location of sponge Dysidea avara in the Mediterranean Sea was also chosen in an area where $D$. avara was found in abundance which was found as good indicator of culture (Decaralt et al., 2010). Osinga et al., (1999) also states that the physical conditions of the culture locations were found to determine the culture success to a great extent. Understanding the physical and biological variables of environment are important (Duckworth et al., 2004) as sponges are suspension feeders and their feeding will be influenced by water current. Also, water temperature will have a significant impact on 
growth and reproduction (Huang et al., 2016). Though high water flow has been found to promote growth of sponges, the relationship was not linear, whereas depth influenced the final size of transplanted sponges (Duckworth et al., 2004), and sponges also grew better in sheltered areas (Duckworth et al., 1997). In another study by Vinod et al., (2009), Spirastrella inconstans cultured in Kerala coast showed an increase in growth from 149 to $175 \mathrm{~mm}, 104$ to $116 \mathrm{~mm}$, and 121 to 132 $\mathrm{mm}$ (in three live specimens) in one month period.

In Andaman Islands, more than 100 sponge species are reported and few works on the antibacterial activities of bacteria associated with Stylissa sp. (Krishnan et al., 2014a; antimicrobial activity of bacteria associated with Ircinia sp. (Krishnan et al., 2014b) and antibacterial activity of Pseudoceratina purpurea (Suman et al., 2013) were carried out. In Andaman Islands, attempts were made to culture marine sponges Stylissa massa and Liosina paradoxain cages (in situ) and in land based aquaria (ex situ) over a period of 120 days (Sankar et al., 2016). Growth and survival were evaluated using four substrates viz., tile, block, coral rock and rope under both in situ and ex situ conditions. $L$. paradoxa in cages recorded significant increase $(\mathrm{p}<0.05)$ on day 90 i.e., by $70 \%$ compared to initial volume whereas at 120 days there was a significant $(\mathrm{p}<0.05)$ decrease (54.22\%). S. massa showed significant increase $(\mathrm{p}<0.05)$ in growth by $95.6 \%$ at 120 days compared to initial volume. Negative growth was recorded in $S$. massa under aquarium conditions while $L$. paradoxa recorded good growth as well as survival and performed exceptionally well in aquarium during the entire experimental period of 120 days. In cages, $90.62 \%$ survival was recorded for $S$. massa in 120 days. Among the different substrates used, coral rocks gave $100 \%$ survival whereas other substrates such as tiles, blocks and ropes showed $87.5 \%$ survival. Under aquarium conditions, $S$. massa, showed an overall survival of $81.25 \%$ and among the different substrates, $100 \%$ survival was obtained with coral rocks, $87.5 \%$ with blocks, $75 \%$ with ropes and the lowest survival of $62.5 \%$ was recorded with tiles. These studies have given encouraging results on the possibilities of sponge culture in Indian conditions. Measurement of exact growth remains a hurdle in these studies as measuring growth with height, length and breadth might not be accurate. Advanced growth measurement methods are to be followed to monitor their growth pattern. Also, long-term experiments are required, since sponges require a minimum of one or two years to reach the harvestable size. The candidate species which have more applications in pharmaceutical and drug industry should be prioritized for mariculture. Since sponge culture is still in infancy in India, several studies are required to standardize the culture techniques as per species and culture conditions. Considering the future potential, such studies are to be initiated to address the supply issue.

\section{Some of the candidate sponges for mariculture in India}

The potential of marine sponge Dysidea avara has been thoroughly discussed (Sipkema et al., 2005b; Decaralt et al., 2010; Osinga et al., 2010; Tommanaro et al., 2015) as they produce avarol, an important metabolite which has several potential applications. Their culture practices has been demonstrated and higher survival rates of over $90 \%$ has been reported (Osinga et al., 2010). Studies on bioactive compounds from Dysidea fragilis are reported from Mandapam coast of Tamil Nadu (Venkateshwarlu et al., 1998) and Dysidea herbacea in Andaman Islands (Venkateshwarulu et al., 1994). Dysidea herbacea is reported to have new 
amino acid Dysiherbaine which is glutamate receptor antagonist (Sakai et al., 1997). Sponges of Mycale genus are an important source of several bioactive metabolites (Huang et al., 2016). Mycale mytilorum was reported by Vinod et al., (2014) from Ernakulam to Kollam in Kerala coast of India whereas $M$. crassissima and $M$. Indica were reported from Andaman Islands (Pattanayak 2006). Stylissa massa is one of the most important sponges concerned with pharmaceutical and drug development. Several compounds like Hymenialdisine, an alkaloid with potential against human neurodegenerative diseases have been found from $S$. massa. Eight alkaloids were derived from these sponges which has potential as anti-tumour (Tasdemir et al., 2002). Their extensive availability in India could be utilized for development of culture technologies. Studies on bioactive metabolite production in cultured sponges were also attempted in Echinodictyum gorgonoides and Callyspongia subarmigerain India (Lipton and Shine, 2009). Hyrtios erectus, another marine sponge from India has been shown to have significant anti proliferative effects against variety of human cancer cell lines (Ramachandran et al., 2013), several alkaloids, Scarlane sesterterpenes (Ashour et al., 2007) and inhibitory activity against hepatocellular carcinoma, colorectal carcinoma and breast adenocarcinoma cells. Plakortis sp. are known for the production of cyclic peroxides (Laport et al., 2009) which are effective against parasitic diseases. Marine sponge Dendrilla nigra reported from India is a reliable source for the development of shrimp therapeutants and studies suggest that Dendrilla medication may form a suitable alternative to replace conventional antibiotics (Selvin and Lipton, 2004a). Despite several growth studies carried out globally, there is only limited understanding on the exact needs of sponges to improve growth (Koopmans et al., 2009). Hence several growth trials will be required to standardize the culture of sponges in Indian waters. With their proven merits, initially sponges like Stylissa massa, Dysidea sp. and Hyrtios erectus could be attempted on long term (1to 2 years) to study their growth and survival pattern. Since several culture methods were reviewed, trials to standardize the various culture methods (ropes horizontal \& vertical), mesh bags, trays, shish kabab, cages, panels etc. can be explored for standardization. In India, several potential sponges are found distributed in regions like Gulf of Mannar, Palk Bay and Andaman Islands, culture practices should be prioritized in these regions. Selvin and Lipton (2004b) reported Kanyakumari Coast to be an excellent area for collection of diverse species of marine sponges which are landed as bycatch in fishing nets. The sponges caught as by-catch were also utilized as source material for the development of novel shrimp therapeutants (Selvin and Lipton, 2004a). Attempts to culture potential species on largescale in suitable locations for a longer duration could help to standardize the shortfalls in culture and develop feasible culture technology for the steady supply of metabolites. In situ cultivation of sponges can be prioritized in early stages as establishing cultures in land-based cultivation for longterm could be cumbersome. Methods such as rope (vertical and horizontal) culture, mesh culture and cages can be evaluated in early stages and suitable modifications in culture systems can be introduced according to the growth and survival pattern of sponges.

\section{Sponge and fish culture: Possibilities of integrated farming systems}

The concept of integrated multitrophic aquaculture is gaining importance now-adays, as this system combines a number of complementary organisms at farm site to optimise nutrient utilization and reduce solid waste (Granada et al., 2015).Fish-sponge 
integrated aquaculture could be one such interesting combination with sponges being filter feeders could act as biofilters. Bath sponge and pearl oyster farms are suggested as feasible natural pollution filtration system in studies on bioremediation mariculture in Zanzibar (Oakland, 2013). Milanese et al., (2003) in his experiments on clearance tests of the sponge Chondrilla nucula suggested this species to be suitable for marine environmental bioremediation, as one square meter patch of this sponge can filter up to $141 / \mathrm{h}$ of sea water. Stabili (2006) also demonstrated the high efficiency of Spongia officinalis var. Adriatica in removing bacteria and suggested the suitability of this species for bioremediation. Such interesting observations holds much promise for integration of sponge and fish culture as sponges could keep the culture environment clean. Interestingly, Osinga et al., (2010) attempted to combine the mariculture offish (sea bass) with the culture of two Mediterranean sponges, Dysidea avara and Chondrosia reniformis under floating fish cages and found culturing of $D$. avara to be feasible under floating cages. Large-scale sponge culture could have a profound effect on the water quality in the vicinity of fish farms, with stimulation in sponge growth making more efficient (Granada et al., 2015). Though the concept is discussed, it is not applied on a commercial scale. Marine cage fish farming being a prominent mariculture activity in India wherein fishes like cobia, pompano, are being cultured across the country. Cage culture demonstration activities are being undertaken in Andaman Islands, Mandapam coast (Tamil Nadu), Veraval coast (Gujarat), Kerala and in coastal areas of the country. Places like Andaman Islands, and Mandapam coast hosts several sponge species and they could be ideal sites for preliminary attempts on sponge culture with fishes. The idea of such integration if proven beneficial in Indian waters could popularise the much deserved attention for sponge culture in the country. Sponges clearly fulfil a number of functional roles across temperate, tropical and polar ecosystems (Bell 2008) and their culture could have beneficial effect on the marine environment apart from the interest on bioactive compounds.

Marine organisms are well known to have specific relationship with numerous microorganisms and sponges are no exception (Thakur and Muller, 2004), as sponges hosts various bacteria, fungi which have been found to possess several bioactive compounds. The association of these microbes with sponges makes them more potential for several applications in drug development field. Hence they need to be harvested sustainably without harming their available natural stock. Sponge farming provides possible solution to the problem of declining wild stocks (Pronzato, 1999) in the era of climate change events which are set to influence the marine world. Considering its potential, sponges could be the future of farming globally because of the demand and the simple methods used for cultivation. Though lack of apparent success in farming methods and production, still they possess enormous scope for mankind. Importance of sponges have been understood globally and countries like the United States of America, New Zealand and parts of Europe have been actively engaged in researches on sponge culture in indoor and outdoor conditions. In India, seaweeds has gained more attention as they possess ample application in various fields of pharmaceutics, cosmetics and food industry. Seaweed farms are functional in places like Mandapam coast, Tamil Nadu as a source of livelihood for coastal communities. Sponges also possess similar potential, and in fact more in terms of their application in drug development and disease curing capabilities. Diseases like malaria, tuberculosis, HIV and cancer is already claiming thousands of lives in 
developing countries like India and marine sponges has proven their potential in developing a cure for such diseases. Methods like chemical synthesis, biotechnological production, cell culture, in vitro culture are being explored to produce the sponges and their metabolites in required quantities. Developing culture technologies for mass production of sponges in either indoor or open sea could solve the supply issue. With such high diversity of marine sponges in India, culture attempts of potential species should be initiated to meet the future demand. Attempts on sponge-fish integration could be a viable avenue and more serious attempts are required to assess its feasibility in India. Sponge derived medicines and drugs could help to alleviate the future challenges of developing countries. In Indian conditions, with the increasing population and disease outbreaks, sponge could be seen as future of farming and the study calls for increased attention and research in sponge mariculture for the welfare of mankind and livelihood.

\section{Acknowledgements}

The authors are thankful to the Indian council of Agricultural Research, New Delhi and the Director, ICAR-Central Island Agricultural Research Institute, Port Blair for providing the necessary support and guidance to carry out the work.

\section{References}

Anjum, K., Abbas, S.Q., Shah, S.A.A., Akhter, A., Batool, S. and Hassan, S.S.U. 2016. Marine sponges as drug treasure. Biomol. Ther., 24(4): 347-362.

Ashour, M. A., Elkhayat, E. S., Ebel, R., Edrada, R. and Proksch, P. 2007.Indole alkaloid from the Red sea sponge Hyrtios erectus. ARKIVOC, Pp. 225-231.

Bari, G.D., Cardone, F., Gaino, E., Liuzzi, G.M., Marzano, C. N., Scoccia, F.and Corriero, G. 2014. Biological variations in a long term ex situ cultivation: a Mediterranean demosponge as model system. Medit. Mar. Sci., 16(1): 73-81.

Battershill, C.N. and Page, M.J. 1996.Sponge aquaculture for drug production. Aquac. Updates, 16: 5-6.

Becerro, M.A., Turon, X. and Uriz, M.J.1997. Multiple functions for secondary metabolites in encrusting marine invertebrates J.Chem.Ecol., 23: 15271547.

Belarbi, E.H., Dominguez, M. R., Garcia, M.C., Contreras Gomez, A., Camacho, F.G. and Grima, E.M. 2003. Cultivation of explants of the marine sponge Crambe crambe in closed systems. Biomol. Eng., 20: 333-337.

Bell, J. J. 2008. The functional role of marine sponges. Estuar. Coast. and Shelf. Sci., 79: 341-353.

Bergman, O., Mayzel, B., Anderson, M. A., Shpigel, M., Hill, R.T. and Ilan, M. 2011.Examination of marine based cultivation of three demosponges for acquiring bioactive marine natural products. Mar. Drugs., 9: 2201-2219.

Caraballo, J. L., Naranjo, S. A. and GarciaGomez, J. C. 1996. Use of marine sponges as stress indicators in marine ecosystems at Algeciras Bay (Southern Iberian Peninsula). Mar. Ecol. Prog. Ser., 135:109-122.

Chairman, K., Singh, A.J.A.R. and Ramesh, M. 2012.Screening twelve species of sponges for biomedical activity in Gulf of Mannar, Tuticorin Coast. Int. J. Mar. Sci., 2(6): 43-50.

Chandra, K.C., Raghunathan, C.and Mondal, T. 2016.Sponges of India. Published by the Director, Zoological survey of India, Kolkata, released during National workshop on Current status of marine faunal diversity of India.

Crawshay, L. R.1939. Studies in the market sponges growth from the planted cutting. J. Mar. Biol. Assoc. U.K., 23: 553-574.

De Voogd, N. J. 2007b. The mariculture potential of the Indonesian reef-dwelling sponge Callyspongia (Euplacella) biru: 
Growth, survival and bioactive compounds. Aquaculture, 262: 54-64.

De Voogd, N. J. and Cleary, D.F.R. 2008.An analysis of sponge diversity and distribution at three taxonomic levels in the Thousand Islands/Jakarta Bay reef complex, west Java, Indonesia. Mar. Ecol., 29:205-215.

De Voogd, N.J. 2007a. An assessment of sponge mariculture potentials in the spermonde archipelago, Indonesia. J. Mar. Biol. Ass. U.K., 87, 5733: 1-8.

Decaralt, S., Agell, G. and Uriz, M.J. 2003. Long term culture of sponge explants: conditions enhancing survival growth and assessment of bioactivity. Biomol. Eng., 20: 339-347.

Decaralt, S., Anchez-Fontenla, J.S., Uriz, M.J. and Wijffels, R.H. 2010.In situ aquaculture methods for Dysidea avara (demospongiae, porifera) in the Northwestern Mediterranean. Mar.Drugs., 8(6): 1731-1742.

Decaralt, S., Otjens, H., Uriz, M.and Wijffels, R.H. 2007.Cultivation of sponge larvae: Settlement, survival, and growth of juveniles. Mar. Biotechnol., 9:592-605.

Decaralt, S., Uriz, M. J. and Wijffels, R.H. 2008. Grazing, differential size-class dynamics and survival of the Mediterranean sponge Corticium candelabrum. Mar. Ecol. Prog. Ser., 360: 97-106.

Devi, P., Wahidulla, S., Kamat, T. and Dsouza, L. 2011. Screening marine organisms for antimicrobial activity against clinical pathogens. Ind. J. Mar. Sci., 40(3): 338346.

Diaz, M. C. and Rutzler, K. 2001.Sponges as essential component of Caribbean coral reefs. Bull. Mar. Sci., 69 (2): 535-546.

Dikid, T., Jain, S.K., Sharma, A., Kumar, A. and Narain, J.P. 2013. Emerging and re emerging infections in India: An overview. Ind. J. Med. Res., 138: 19-31.

Dinakaran, D.I. and Lipton, A.P. 2012.Antimicrobial potential of the marine sponge Sigmadocia pumila from the South eastern region of India. Wor. J.
Fish. M. Sci., 4(4): 344-348.

Duckworth, A. 2009. Farming sponges to supply bioactive metabolites and bath sponges: a review. Mar. Biotechnol., 11(6): 669-679.

Duckworth, A. and Battershill, C. N. 2003b. Sponge aquaculture for the production of biologically active metabolites: the influence of farming protocols and environment. Aquaculture, 221: 311-329.

Duckworth, A. and Battershill, C. N. 2003a. Developing farming structures for production of biologically active sponge metabolites. Aquaculture, 217(1-4): 139156.

Duckworth, A. R. 2000.Aquaculture of sponges for production of bioactive metabolites. Zoology. University of Canterbury, Christchurch, pp. 186.

Duckworth, A. R., Battershill, C. N. and Bergquist, P. R. 1997. Influence of explant procedures and environmental factors on culture success of three sponges. Aquaculture, 165: 251-267.

Duckworth, A. R., Battershill, C. N. and Schiel, D. R. 2004. Effects of depth and water flow on growth, survival and bioactivity of two temperate sponges cultured in different seasons. Aquaculture, 242: 237250.

Duckworth, A., Wolff, C. and Evans-Illidge, E. 2009.Farming bath sponges in tropical Australia. World Aquacult., pp. 20-22.

Duckworth, A., Wolff, C., Evans-Illidge, E., Morris, J., Lowatta, S., Naawi, S., Lowatta, P. and Mosby, P. 2007. Exploring the potential of bath sponge aquaculture in Torres strait. CRC Torres strait Research Task Final Report, 1-54.

Elhady, S. S., El-Halawany, A.M., Alahdal, A. M., Hassanean, H.A. and Ahmed, S.A. 2016. A new bioactive metabolite isolated from the Red Sea marine sponge Hyrtios erectus, Molecules, 21(82):1-9.

Francis, J. C., Bart, L. and Poirrier, M. A.1990.Effect of medium $\mathrm{pH}$ on the growth rate of Ephydatia fluviatilis in laboratory culture. In: Rutzler, K. (ed.). New Perspectives in sponge biology. 
Smithsonian Institution Press, Washington, D.C., pp. 485-490.

Gordaliza, M. 2010. Cytotoxic terpene quinines from marine sponges. Mar. Drugs., 8: 2849-2870.

Granada, L., Sousa, N., Lopes, S. and Lemos, M. F. L. 2015. Is integrated multitrophic aquaculture the solution to the sectors' major challenges? - a review. Rev. Aquacult. 6:1-18.

Hadas, E., Shpigel, M.and Ilan, M. 2005. Sea ranching of the marine sponge Negombata magnifica (Demospongiae, Latrunculiidae) as a first step for latrunculin B mass production. Aquaculture, 244: 159-169.

Hoffmann, F., Rapp, H.T., Zoller, T.and Reitner, J. 2003. Growth and regeneration in cultivated fragments of the boreal deep water sponge Geodia barrette Bowerbank, $1858 \quad$ (Geodiidae, Tetractinellida, Demospongiae) J. Biotechnol., 100: 109-118.

Huang, D., Ou, H., Wang, D. and Chen, J. 2016. Sexual reproduction of the potentially cultivable sponge Mycale phyllophila (Porifera: Demospongiae). J. Mar. Biol. Assoc. U.K., 96(5): 1073-1081.

Inbakandan, D., Sivaleela, G., Peter, D.M., Kirubagaran, R., Venkatesan, R. and Khan, S. A. 2012. Marine sponge extract assisted biosynthesis of silver nanoparticles. Mater.Lett., 87 66-68.

Ireland, C.M., Copp, B.R., Foster, M.P., McDonald, L.A.,Radisky, D.C.and Swersey, J.C. 1993. Biomedical potential of marine natural products. In: Attaway, D.H., Zaborsky, O.R. (eds), Marine biotechnology. Pharmaceutical and bioactive natural products, vol. 1 Plenum, New York, pp. 1-43.

Kinne, O. 1977. Cultivation of animals-research cultivation, 3: porifera. In: Marine Ecology, Vol III (cultivation), part 2, Kinne, O. (ed.). London: Wiley Interscience, 5(1) 627-64.

Kiruba-Sankar, R., Chadha, N. K., Dam-Roy,S., Paromita-Banerjee, Saharan, N. and Krishnan, P. 2016. Marine Sponges as
Biological Indicators of Oligotrophic Andaman waters. Ind. J. Mar. Sci., 45(2): 338-341.

Kloppel, A., Pfannkuchen, M., Putz, A., Proksch, P. and Brummer, F. 2008. Ex situ cultivation of Aplysina aerophoba close to in situ conditions: ecological, biochemical and histological aspects. Mar.Ecol., 29(2): 259-272.

Koopmans, M. 2009. Growth and metabolism of sponges. Ph.D. thesis, Wageningen University, The Netherlands.

Koopmans, M., Martens, D. and Wijffels, R.H. 2009. Towards commercial production of sponge medicines. Mar. Drugs., 7(4): 787-802.

Koopmans, M., Rijswijk, P.V., Martens, D., Egovora- Zachernyuk, T.A. Middelburg, J.J. and Wijffels, R.H. 2011.Carbon conversion and metabolic rates in two marine sponges. Mar. Biol., 158: 9-20.

Krishnan, K. A. A. and Keerthi, T. R. 2016. Analyses of methanol extracts of two marine sponges Spongia officinalis var ceylonensis and Sigmadocia carnosa from Southwest coast of India for their bioactivities. Int. J. Curr. Microbiol. App. Sci., 5(2): 722-734.

Krishnan, P., Balasubramaniam, M., Roy, S.D., Sarma, K., Hairun, R. and Sunder, J. 2014a. Characterization of the antibacterial activity of bacteria associated with Stylissa sp., a marine sponge. Adv. Anim. Vet. Sci., 2(1): 2025.

Krishnan, P., Veeramani, S., Damroy, S., Sarma, K., Kumar, P. and Sunder, J. 2014b. Antimicrobial activity of Ircinia sp.- a marine sponge and its associated bacteria from Andaman Coast. Adv. Anim. Vet. Sci., 2(1): 37-41.

Krishnan, P., Immanuel, T., Raghunathan, C., Sankar, R. K. and Roy, S. D. 2012. Sponge diversity in the Andaman and Nicobar Islands: status and issues. In: Singh, D.R. et al., (eds.), Souvenir, National Seminar on Innovative Technologies for conservation and sustainable utilisation of island 
biodiversity. CARI, Port Blair, pp. 102109.

Kumar, M. S., Vijayalaxmi, K. K.and Pal, A. K. 2014. Antiinflamatuvar and antioxidant properties of Spongosorites halichondriodes, a marine sponge. Turk. J. Pharm. Sci., 11(3): 285-294.

Laport, M.S., Santos, O. C. S. and Muricy, G. 2009. Marine sponges: Potential source of new anti microbial drugs. Curr. Pharm. Biotechnol., 10: 86-105.

Ledda, F.D., Pronzato, R.and Manconi, R. 2014. Mariculture for bacterial and organic waste removal: a field study of sponge filtering activity in experimental farming. Aquacult. Res., 45(8): 13891401.

Lipton, A.P. and Shine, S. 2009. Mariculture of marine sponges for drug development: bioactivity potentials of cultured sponges, Callyspongia sub armigera. (Ridley) and Echinodictyum gorgonoides (Dendy) Mar. Fish. Inf. Ser. T. \& E. Ser., 202.

Longakit, M. B., Sotto, F. B. and Kelly, M. 2005. The shallow water marine sponges (Porifera) of Cebu, Phillipines. Science Diliman, 17(2): 52-74.

MacMillan, S. M. 1996.Starting a successful commercial sponge aquaculture farm. University of Hawaii Sea Grant College Program Communications Office, School of Ocean and Earth Science and Technology, CTSA publication 120.

Milanese, M., Chelossi, E., Manconi, R., Sara, A., Sidri, M. and Pronzato, R. 2003. The marine sponge Chondrilla nucula Schmidt, 1862 as an elective candidate for bioremediation in integrated aquaculture. Biomol. Eng., 20: 363-368.

Moore, H.F. 1910. A practical method of sponge culture. Bull. U.S. Bur. Fish., 28: 545-585.

Muller, W. E. G., Wimmer, W., Schatoon, W., Bohm, M., Batel, R. and Filic, Z. 1999. Initiation of an aquaculture of sponges for the sustainable production of bioactive metabolites in open systems: Example, Geodia cydonium. Mar. Biotechnol. 1(6): 569-579.
Muller, W. E., Maidhof, A.,Zahn, R.K., Schroder, H.C., Gasic, M.J., Heidemann, D., Bernd, A., Kurelec, B., Eich, E. and Seibert, G.1985. Potent antileukemic activity of the novel cytostatic agent avarone and its analogues in vitro and in vivo Cancer. Res., 45(10): 4822-6.

Munro, M.H.G., Blunt, J.W., Dumdei, E.J., Hickford, S. J. H., Lill, R.E., Li, S., Battershill, C. N. and Duckworth, A.R. 1999.The discovery and development of marine compounds with pharmaceutical potential. J.Biotechnol., 70: 15-25.

Muricy, G. 1989. Sponges as pollution biomonitors at Arraial do cabo, Southeastern Brazil. Rev. Brasil. Biol., 49(2): 347-354.

Nickel, M. and Brummer, F. 2003. In vitro sponge fragment culture of Chondrosia reniformis (Nardo, 1847). J. Biotechnol., 100: 147-159.

Oakland, H. 2013. Bioremediation mariculture in Zanzibar, Tanzania: A viability assessment of using bath sponges and pearl oyster farms to filter highly polluted waters in the Zanzibar channel. Independent Study Project (ISP) Collection Paper 1526.

Ong, C., Lim, J.Z., Ng, C.T., Li, J.J., Yung, L.Y. and Bay, B.H. 2013. Silver nanoparticles in cancer: therapeutic efficacy and toxicity. Curr. Med. Chem., 20(6): 772-81.

Oronti, A., Danylchuk, A.J., Elmore, C.E., Auriemma, R. and Pesle, G. 2012. Assessing the feasibility of sponge aquaculture as a sustainable industry in the Bahamas. Aquac. Int., 20(2): 295-303.

Osinga, R., Belarbi, E. H., Molina, G. E., Tramper, J. and Wijffels, R.H. 2003. Progress towards a controlled culture of the marine sponge Pseudosuberites andrewsi in a bioreactor. J. Biotechnol., 100: 141-146.

Osinga, R., Sidri, M., Cerig, E., Gokalp, S.Z. and Gokalp, M. 2010. Sponge aquaculture trials in the East-Mediterranean Sea: new approaches to earlier ideas open. Mar. Bio. J., 4: 74-81. 
Osinga, R., Tramper, J. and Wijffels, R. H. 1999. Cultivation of marine sponges. Mar. Biotechnol., 1: 509-532.

Page, M. J., Northcote, P. T., Webb, V. L., Mackey, S. and Handley, S. J. 2005. Aquaculture trials for the production of biologically active metabolites in the New Zealand sponge Mycale hentscheli (Demospongiae: Poecilosclerida). Aquaculture, 250(1-2): 256-269.

Pattanayak, J. G. 2006. Marine sponges of Andaman and Nicobar Islands. Rec. Zool. Sur. India, Occasional Paper No. 255: 164.

Pedpradab, P., Molex, W., Nukoolkarn, V. and Darumas, U. 2010. Biological activities of extracts from Andaman sea sponges, Thailand Eur. Asia. J. Bio. Sci., 4:63-69.

Pereira, R.C., Carvalho, A. G.V., Gama, B.A.P. and Coutinho, R. 2002. Field experimental evaluation of secondary metabolites from marine invertebrates as antifoulants. Brazilian. J. Bio., 1-15.

Pietschmann, R., Shatton, M. and Schatton, W. 2004. Process for preparation of compositions with a high content in avarol and their use. Eur. Pat. EP1391197.

Pronzato, R. 1999. Sponge-fishing, disease and farming in the Mediterranean Sea. Aquat. Conserve. (9): 485-493.

Pronzato, R., Bavestrello, G., Cerrano, C., Magnino, G., Manconi, R., Pantelis, J., Sara, A. and Sidri, M. 1999. Sponge farming in the Mediterranean Sea: New perspectives. Memoirs of the Queensland Museum.

Ramachandran, M., Immanuel, T., Backyavathy, M. and Nambikkairaj, B. 2013. In vitro determination of marine sponge Hyrtios erectus secondary metabolite effect against human breast and larynx cancer cell lines. Inter. J.Curr. Res., 5(2): 124-128.

Riberio, S. M., Bianco, E.M., Rogers, R., Souza, C.F. and Pereira, R. C. 2012. Antifoulant property of the marine sponge Hymeniacidon heliophila (Demospongiae: Holichondrida). Braz. J.
Oceanography, 60(2): 255-257.

Sakai, R., Kamiya, H., Murata, M. and Shimamoto, K. 1997. A new neurotoxic amino acid from the Micronesian marine sponge Dysidea herbacea. J. Am. Chem. Soc., 119, 4112-116.

Sankar, K.R., Chadha, N.K., Dam-Roy, S., Paromita-Banerjee, Saharan, N. and Krishnan, P. 2016. Growth and survival of marine sponges Stylissa massa and Liosina paradoxa in sea and land based culture systems. Ind. J. Fish., 63(4): 5560.

Schiefenhovel, K. and Kunzmann, A. 2012. Sponge farming trials: survival, attachment, and growth of two IndoPacific sponges, Neopetrosia sp. and Stylissa massa. J. Mar. Bio., doi:10.1155/2012/417360.

Schippers, K. J., Sipkema, D., Osinga, R., Smidt, H., Pomponi, S.A., Martens, D.E. and Wijffels, R. H. 2012. Cultivation of sponges, sponge cells and symbionts. Adv. Mar. Biol., 62: 273-337.

Selvin, J. and Lipton, A. P. 2004a. Dendrilla nigra a marine sponge as potential source of antibacterial substances for managing shrimp diseases. Aquaculture, 236: 277283.

Selvin, J. and Lipton, A. P. 2004b. Biopotentials of secondary metabolites isolated from marine sponges. Hydrobiol., 513: 231- 238.

Selvin, J., Ninawe, A. S., Kiran, G. S.and Lipton, A. P. 2010. Sponge microbial interactions: Ecological implications and bioprospecting avenues. Crit. Rev. Microbiol., 36(1): 82-90.

Sipkema, D., Franssen, M. C. R., Osinga, R., Tramper, J. and Wijffels, R. H. 2005a. Marine sponges as pharmacy. Mar. Biotechnol., 7: 142-162.

Sipkema, D., Osinga, R., Schatton, W., Mendola, D., Tramper, J. and Wijffels, R.H. 2005b. Large scale production of pharmaceuticals by marine sponges: Sea, cell or synthesis? Biotechnol.Bioeng., 90(2): 201-22.

Sivaleela, G. 2014. Marine sponges of Gulf of 
Mannar and Palk Bay. Rec. Zool. Surv. India, 114(part 4): 607-622.

Sonia, G. A. S. and Lipton, A. P. 2012.Mosquito larvicidal activity of marine sponge metabolites. Glo. J. Pharmacol., 6(1): 1-3.

Sonia, G. A. S., Lipton, A. P. and Raj, R. P. 2008. Antibacterial activity of marine sponge extracts against fish pathogenic bacteria. Isr. J. Aqua., 50(3): 172-176.

Stabili, L., Licciano, M., Giangrande, A., Longo, C., Mercurio, M., Marzano, C., Nand Corriero, G. 2006.Filtering activity of Spongia officinalis var.adriatica (Schmidt) (Porifera, Demospongiae) on bacterioplankton: implications for bioremediation of polluted seawater. Water. Res., 40(16): 3080-90.

Stevely, J. and Sweat, D.1985.Survival and growth of cut $v s$ hooked commercial sponges in the Florida Keys. Florida Sea Grant Extension Programme Technical paper No.38: 1-12.

Stevely, J. M., Thompson, J. C. and Warner, R.E. 1978. The biology and utilization of Florida's commercial sponges. Florida Sea Grant Technical paper No.8:1-45.

Stone, A.R. 1970. Growth and reproduction of Hymeniacidon perleve (Porifera) in Langstone harbour, Hampsire. J. Zool. Lond., 161: 443-459.

Suman,T., Kaleeswaran, B., Titus-Immanuel, Roy, S.D. and Krishnan, P. 2013. Antibacterial activity of Pseudoceratina purpurea - A marine sponge from Andaman. Res. J. Pharm. Tech.,.5(5): 544-549.

Swatscheck, D., Schatton, W., Kellermann, J., Muller, W.E.G. and Kreuter, J. 2002. Marine sponge collagen: Isolation, characterization qne effects on the skin parameters surface-pH, moisture and sebum. Eur. J. Pharm. Biopharm., 53: 107-113.

Tasdemir, D., Mallon, R., Greenstein, M., Feldberg, L.R., Kim, S.C., Collins, K., Wojciechowicz, D., Mangalindan, G.C., Concepcion, G. P., Harper, M. K. and Ireland, C.M. 2002. Aldisine alkaloids from the Philippine sponge Stylissa massa are potent inhibitors of mitogen-activated protein kinase kinase-1 (MEK-1). J. Med. Chem., 45(2): 529-532.

Thakur, N.L. and Muller, W.E.G. 2004. Biotechnological potential of marine sponges. Curr. Sci,, 86(11): 1506-1512.

Thomas, P.A. 1998. Faunal diversity in India: Porifera. In: Faunal diversity in India (eds: Alfred, das and Sanyal) ENVIS ZSI Kolkata 27-36.

Tommonaro, G., Iodice, C., AbdEl-Hady, F.K., Guerriero, G. and Pejin, B. 2015. The Mediterranean sponge Dysidea avara as a 40 year inspiration of marine natural product chemists. Biodiveristy and Endangered species, S1: S1.001. doi:10.4172/2332-2543.S1.001.

Vansoest, R.W.M., Boury-Esnault, N., Vacelet, J., Dohrmann, M., Erpenbeck, D.,de Voogd, N.J., Santodomingo, N., Vanhoorne, B., Kelly, M. and Hooper, N. A.J. 2012. Global Diversity of Sponges (Porifera). PLoS One, 7: 1-23.

Venkataraman, K. 2005. Coastal and marine biodiversity of India. Ind. J. Mar. Sci., 34(1): 57-75.

Venkateshwarlu, Y., Reddy, N. S. and Ramesh, P. 1998. A new oxygenated Furano Sesquiterpene from the sponge Dysidea fragilis. Nat. Prod. Sci., 4(3): 158-160.

Venkateshwarulu, Y., Biabani, M.A. F., Reddy, M.V.R. and Chavakula, R. 1994. A new Sesquiterpene from the Andaman sponge Dysidea herbacea. J. Nat. Prod., 57(6): 827-828.

Verdenal, B. and Vacelet, J. 1990. Sponge culture on vertical ropes in the Northwestern Mediterranean Sea. In: Rutzler, K. (Ed.), New Perspectives in Sponge Biology. Smithsonian Institution Press, Washington DC, pp. 416-424.

Vijayalakshmi, S. 2015. High throughput screening for antimicrobial activity of marine sponges. International Journal of Basic and Applied Sciences, 1(1): 9-12.

Vinod, K., George, R. M., Thomas, P.A., Manisseri, M.K. and Shylaja, G. 2014. Diversity and distribution of shallow 
water sponges (Porifera) in the coastal waters from Enayam to Kollam, Southwest coast of India. Ind. J. Fish., 61(3) 52-57.

Vinod, K., George, R.M. and Manisseri, M.K. 2009.Preliminary studies on the growth in captivity of Spirastrella inconstans (Dendy) collected from the intertidal region of Palk Bay, south-east coast of India. Mar. Fish. Inform. Ser., T \& E, Ser., No. 202.

Webster, N.S.2007. Sponge disease: a global threat. Environ. Microbiol., 9(6) 1363-75.

Wilkinson, C. R. and Vacelet, J. 1979. Transplantation of marine sponges to different conditions of light and current. J. Exp. Mar. Biol. Ecol., 37: 91-104.
Wilson, J.J. and Kitto, M.R. 2012.Marine sponges an evolving science- the need for a comprehensive systematic inventory for peninsular India. Curr. Sci., 102(4): 545546.

Xue, L. and Zhang, W. 2009. Growth and survival of early juveniles of the marine sponge Hymeniacidon perlevis (Demospongiae) under controlled conditions. Mar. Biotechnol., 11: 640649.

Yi, Q., Wei, Z., Hua, L., Xingju, Y. and Meifang, J. 2005 Cultivation of marine sponges. Chin. J. Oceanol. Limnol., 23 (2): 194-198.

\section{How to cite this article:}

Kiruba-Sankar, R., K. Vinod, S. Dam Roy, P. Krishnan, N.K. Chadha, Paramita Banerjee Sawant and Neelam Saharan. 2017. Cultivation of Marine Sponges with Pharmaceutical Value: Status and Future Prospects in India. Int.J.Curr.Microbiol.App.Sci. 6(12): 4334-4351. doi: https://doi.org/10.20546/ijcmas.2017.612.498 